Article

\title{
Polyazulene-Based Materials for Heavy Metal Ion Detection. 2. (E)-5-(azulen-1-yldiazenyl)-1H- Tetrazole-Modified Electrodes for Heavy Metal Sensing
}

\author{
Laura-Bianca Enache 1,2, Veronica Anăstăsoaie ${ }^{1,2}$, Liviu Birzan ${ }^{3}$, \\ Eleonora-Mihaela Ungureanu $^{1, *}$, Peng Diao ${ }^{4}$ and Marius Enachescu ${ }^{2}$ (D) \\ 1 Department of Inorganic Chemistry, Physical Chemistry and Electrochemistry, Faculty of Applied Chemistry and \\ Materials Science, University “Politehnica” of Bucharest, Gheorghe Polizu 1-7, Sector 1, 011061 Bucharest, Romania; \\ laura.bianca@cssnt-upb.ro (L.-B.E.); veronica.anastasoaie@onmicrosoft.upb.ro (V.A.) \\ 2 Center for Surface Science and Nanotechnology, University “Politehnica” of Bucharest, Splaiul Independentei 313, \\ 060042 Bucharest, Romania; marius.enachescu@cssnt-upb.ro \\ 3 Institute of Organic Chemistry “C. D. Nenitzescu” of Romanian Academy, Splaiul Independentei 202B, \\ P.O. Box 15-258, 71141 Bucharest, Romania; lbirzan@yahoo.com \\ 4 School of Materials Science and Engineering, Beihang University, Beijing 100191, China; pdiao@buaa.edu.cn \\ * Correspondence: mihaela.ungureanu@cssnt-upb.ro; Tel.: +40-72-465-9287
}

Received: 8 August 2020; Accepted: 6 September 2020; Published: 8 September 2020

\begin{abstract}
Azulene-based materials present very appealing properties for the preparation of advanced materials. They can be irreversibly electrooxidated, leading to polymers, which can be deposited on electrodes and modified. This paper shows several experiments concerning the preparation of modified electrodes based on (E)-5-(azulen-1-yldiazenyl)- $1 H$-tetrazole (L). L has a tetrazole complexing unit, which can be attached to the electrode's surface and recognized. L has been deeply characterized by electrochemical techniques. Complexing modified electrodes have been prepared and tested in different conditions. Functional modified electrodes based on $\mathbf{L}$ obtained by controlled potential electrolysis were examined by AFM and SEM to see the influences of charge and potential on the deposited polyz films' morphologies. The modified electrodes prepared in different conditions have been tested for heavy metal ion sensing. The new azulene-based modified electrode demonstrated its feasibility for $\mathrm{Pb}$ ions analysis (detection limit of $5 \times 10^{-8} \mathrm{M}$, and linear domain between $5 \times 10^{-8} \mathrm{M}$ and $10^{-6} \mathrm{M}$ ) and potential use in future applications for real water samples analysis.
\end{abstract}

Keywords: (E)-5-(azulen-1-yldiazenyl)-1H-tetrazole; voltammetric techniques; modified electrodes; atomic force microscopy; scanning electron microscopy; heavy metal sensing

\section{Introduction}

The classical techniques used to determine heavy metal ions are atomic absorption [1] and emission [2] spectroscopy, cold vapor atomic fluorescence spectrometry [3] and inductively coupled mass spectrometry [4]. These techniques are very sensitive but involve laborious sample preparation processes [5], well-controlled experimental conditions and expensive tools. Some of these disadvantages can be overcome by electrochemical detection, using methods such as anodic stripping voltammetry. The latter has important advantages, such as outstanding sensitivity, low cost and compatibility with turbid and colored samples; it is also a portable method. Chemically modified electrodes (CMEs) have received special attention among the electrodes used for stripping, because they can increase the sensitivity and selectivity of electroanalytical techniques [6], are easy to obtain and are sometimes 
biocompatible [7]. These electrodes can be obtained by covering the electrode with polymeric films. The thickness of the film is easy to control [8]; the method is generally reliable and reproducible. In order to obtain chelated electrodes modified, the most efficient form of preparation is the direct electropolymerization of a complexing monomer [9]. This leads, in a single step, to a complexing polymeric film. Among the monomers used for the functionalization of electrodes, azulene has a special advantage, as it can be polymerized easily due to its polar character. Azulene derivatives have been used little in the electroanalysis of metal ions. For example, azulene-based CMEs were used by our group to detect $\mathrm{Pb}$ (II) and $\mathrm{Cd}$ (II) [10].

Azotetrazoles may be mentioned among the ligands that form complexes with heavy metal ions. They form complexes with $\mathrm{Hg}, \mathrm{Cu}, \mathrm{Cd}, \mathrm{Ag}, \mathrm{Co}, \mathrm{Ni}, \mathrm{Fe}$ and $\mathrm{Pb}$ ions [11]. The binding of azotetrazoles to azulene molecules leads to complexing monomers that can be used to obtain chelating modified electrodes.

This paper presents the electrochemical study of a new azotetrazole monomer, namely, (E)-5-(azulen-1-yldiazenyl)-1H-tetrazole (L). This monomer (Figure 1) was used to obtain modified electrodes in a single step by electropolymerization. Electrodes modified with polyL films were tested for their ability to complex heavy metal ions. Open-circuit chemical preconcentration coupled with the anodic stripping technique has been applied for this purpose in a similar manner by other studies $[10,12]$. Those studies worked towards obtaining sensors for heavy metals with the highest possible performances using new materials-alternatives to the existing ones (having another monomer besides pyrrole and aniline or thiophene) —and the expertise of researchers in azulene synthesis [10-15], in electrochemical characterization of small molecules $[10,11,14,15]$ in obtaining and characterizing modified electrodes based on azulene [10-17] and in the use of sensors for dosing heavy metals (with good results, especially for lead) [18-20]. The present paper proposes the use of an azulene derivative having azotetrazole as a strong attractant of metal ions, in order to create a sensor for heavy metals. Several aspects of morphology for the polymeric films based on azulenes are of interest to be investigated by AFM and SEM [16]. L has been characterized by electrochemistry, and the conditions for the preparation of complexing modified electrodes have been established. They were examined by AFM and SEM to see the influences of charge and potential on the deposited films' morphologies. The complexing modified electrodes have been also tested for the detection of $\mathrm{Hg}$ (II), $\mathrm{Cd}(\mathrm{II}), \mathrm{Cu}$ (II) and $\mathrm{Pb}$ (II) ions in water synthetic solutions. The ability to recognize those metal ions was examined using the newly prepared modified electrodes, and the necessary conditions in view of that purpose were established.

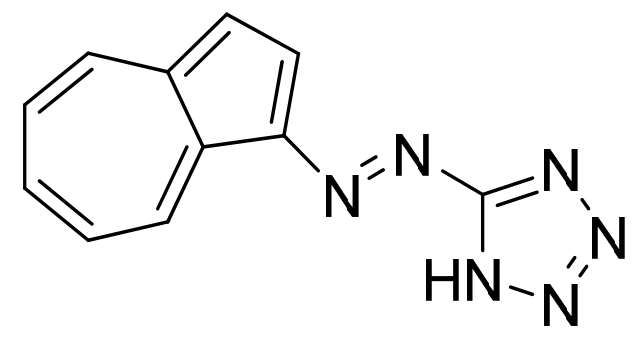

Figure 1. Structure of $\mathbf{L}$.

\section{Materials and Methods}

L was synthesized according to the recently published procedure [11,14]. The experiments concerning its electrochemical behavior were performed in acetonitrile $\left(\mathrm{CH}_{3} \mathrm{CN}\right)$ containing $0.1 \mathrm{M}$ tetrabutylammonium perchlorate (TBAP), both from Fluka (Munich, Germany) — used as the solvent and supporting electrolyte. $\mathrm{Cd}(\mathrm{II})$ nitrate tetrahydrate, $\mathrm{Pb}(\mathrm{II})$ nitrate and $\mathrm{Hg}(\mathrm{II})$ acetate (all from Sigma Aldrich, Taufkirchen, Germany) and $\mathrm{Cu}(\mathrm{II})$ acetate monohydrate (from Fluka), were used to prepare the test solutions of heavy metal ions. 
The PGSTAT 12 AUTOLAB potentiostat (Utrecht, The Netherlands) was connected to a three-electrode cell [10]. The working electrodes were glassy carbon (with $3 \mathrm{~mm}$ diameter) (Metrohm, Herisau, Switzerland) bare or modified with $\mathbf{L}$. They were used for characterization and recognition experiments, respectively. Prior to each determination the working electrode was polished with diamond paste $(2 \mu \mathrm{m})$ on felt, rinsed with solvent afterwards and dried with fine paper. A platinum wire served as an auxiliary electrode, and $\mathrm{Ag} / 10 \mathrm{mM} \mathrm{AgNO}_{3}$ in $0.1 \mathrm{M} \mathrm{TBAP}, \mathrm{CH}_{3} \mathrm{CN}$ or $\mathrm{Ag} / \mathrm{AgCl}, 3 \mathrm{M}$ $\mathrm{KCl}$ served as reference (in electrochemical experiments performed in acetonitrile or water solutions, respectively). The potentials were finally calibrated to the potential of the ferrocene/ferrocenium redox couple $\left(\mathrm{Fc} / \mathrm{Fc}^{+}\right)$in experiments performed in acetonitrile solutions.

Cyclic voltammetry $(\mathrm{CV})$ curves have been recorded at a scan rate of $0.1 \mathrm{~V} / \mathrm{s}$, and differential pulse voltammetry (DPV) curves at $0.01 \mathrm{~V} / \mathrm{s}$, with a pulse height of $0.025 \mathrm{~V}$ and a step time of $0.2 \mathrm{~s}$. Rotating disk electrode voltammetry (RDE) curves were obtained at $0.01 \mathrm{~V} / \mathrm{s}$ at different rotation rates [10].

All experiments have been done at room temperature $\left(25^{\circ} \mathrm{C}\right)$, under an argon atmosphere.

Modified electrodes have been obtained by controlled potential electrolysis (CPE). The heavy metal ion detection has been studied in $0.1 \mathrm{M}$ buffer acetate $(\mathrm{pH}=5.5)$ solution. Metal ion solutions with concentrations between $10^{-4}$ and $10^{-8} \mathrm{M}$ were prepared from their $10^{-2} \mathrm{M}$ stock solutions in water by dilutions. The repeatability evaluated from 3 experiments performed in the same conditions was of about $95 \%$ for CPE (by ferrocene redox probe), $95 \%$ for equilibration and overoxidation (from the superposition of the CV curves in the last cycle) and of about $70 \%$ for accumulation and stripping (from the DPV currents).

Scanning electron microscopy (SEM) measurements using Hitachi SU 8230 equipment (Tokyo, Japan) were carried out with a low acceleration voltage (5 to $10 \mathrm{kV}$ ), to avoid the sample damage.

The atomic force microscopy (AFM) technique has been successfully used to study the surface properties of the polymer-modified glassy carbon electrode $[15,16]$. Topography and roughness properties of the prepared polymer films were investigated via a multimode atomic force microscope (NTEGRA System, NT-MDT, Moscow, Russia). The AFM measurements were performed in tapping mode using a commercially available cone-shaped tip from monocrystalline silicon (having a radius of approximately $10 \mathrm{~nm}$ ) mounted on a cantilever with a stiffness of about $0.26 \mathrm{~N} / \mathrm{m}$. All images ( $512 \times 512$ lines) were acquired in ambient conditions with a $0.3 \mathrm{~Hz}$ scan rate. The root mean square (RMS) roughness parameter was calculated from the acquired topographic images using processing software. RMS and the average roughness $(\mathrm{Ra})$ parameters of the films were calculated from the acquired topographic images using the Equations (1) and (2):

$$
\begin{gathered}
R M S=\sum_{i=1}^{N}\left[\frac{\left(h_{1}-\bar{h}\right)^{2}}{N}\right]^{\frac{1}{2}} \\
R a=\frac{1}{N} \sum_{i=1}^{N}\left|h_{i}-\bar{h}\right|
\end{gathered}
$$

where $h_{i}$ is the height value at each data point, $\bar{h}$ represents the profile mean value of the surface and $\mathrm{N}$ is the number of data points in the analyzed profile.

For SEM and AFM studies, polyL films were prepared on $6 \mathrm{~mm}$ diameter glassy carbon disks (OrigaLys Les Verchères, France) by controlled potential electrolysis (CPE), following the specific procedure established in our laboratory for AFM and SEM investigations [16]. 


\section{Results and Discussion}

\subsection{Electrochemical Characterization of $\mathbf{L}$}

Electrochemical behavior of $\mathbf{L}$ has been examined by CV, DPV and RDE experiments using the previously established procedure [12]. The CV and DPV oxidation and reduction curves have been recorded at several concentrations of $\mathrm{L}(1-2 \mathrm{mM})$ in solutions containing $0.1 \mathrm{M} \mathrm{TBAP}$ in $\mathrm{CH}_{3} \mathrm{CN}_{\text {, }}$ starting from the equilibrium potential (Figure 2). DPV and CV curves in Figure 2 show three oxidation peaks (denoted a1, a02 and a03) and seven reduction peaks (denoted c01, c02, c1 c2, c3, c4 and c5). The notation for DPV peaks has been kept for all processes, at the corresponding potentials.

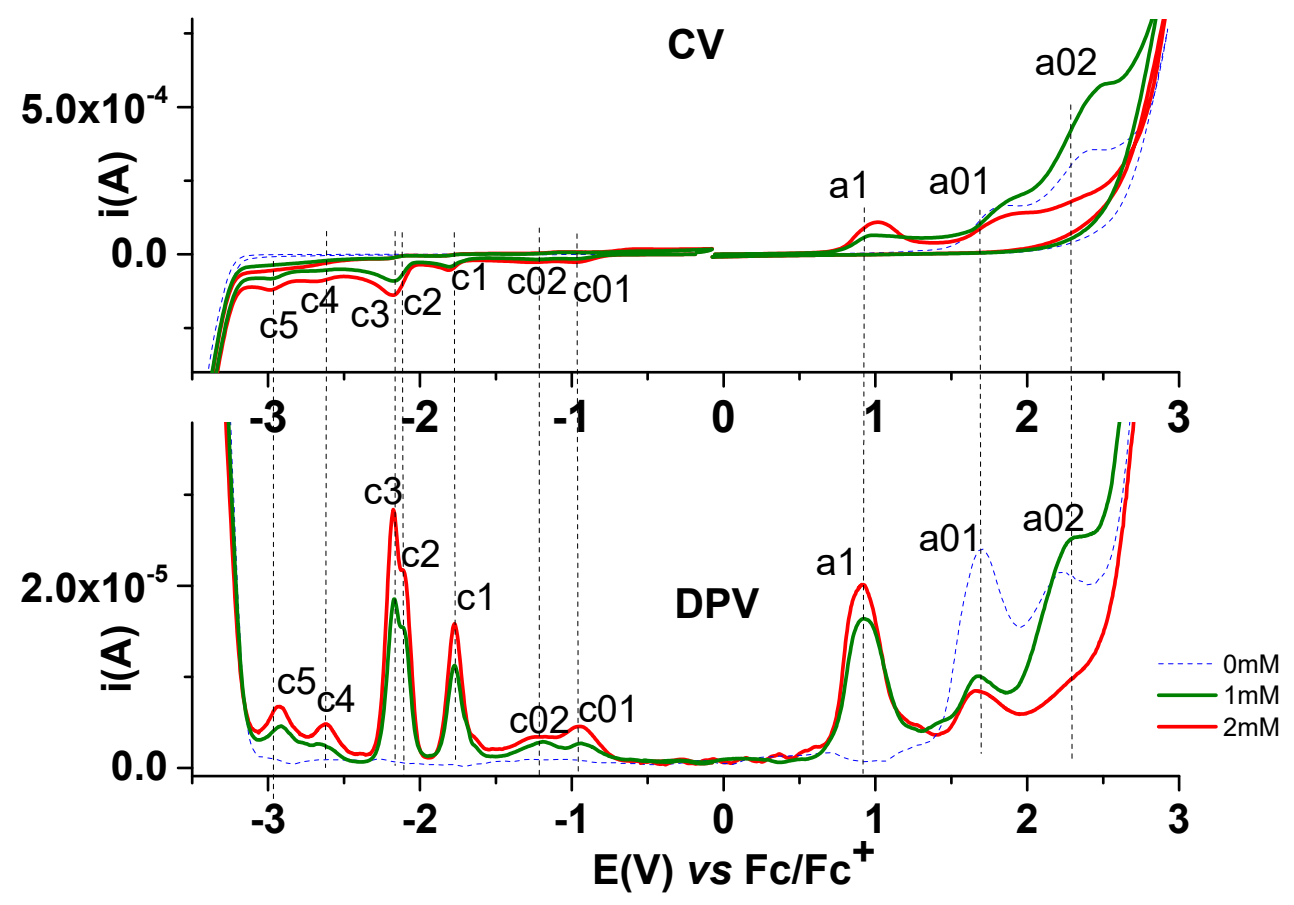

Figure 2. DPV (bellow) and CV (above) curves for $\mathbf{L}$ at different concentrations (0, 1 and $2 \mathrm{mM}$ ); absolute values of DPV currents are shown.

The peaks attributed to the ligand processes, which increase with the concentration of $\mathbf{L}$, have been denoted in the order of their appearance in the anodic (a1) and cathodic (c1-c5) scans. The other signals (a01, a02, c01 and c02), which are not dependent on $\mathbf{L}$ concentration, were attributed to other processes. For instance, the peaks a01 and a02 (with currents decreasing with $\mathrm{L}$ concentration, at 1.73 and $2.48 \mathrm{~V}$, respectively) were due to the oxidation processes of residual water and the formation of oxides in this organic solvent, while the peaks c01 and c02 were due to the presence of small amounts of the decomposed ligand and traces of oxygen. One peak (a1) due to the ligand oxidation appears at about $0.9 \mathrm{~V}$.

Figure 3a presents the CV curves obtained in a $1 \mathrm{mM}$ solution of $\mathbf{L}$ at different scan rates $(0.1-1 \mathrm{~V} / \mathrm{s})$ when scanning in potential domains of the anodic peak a1 or cathodic peak $\mathrm{c} 1$. All current values increase with the scan rate. Linear dependences for the peak currents on the square root of the scan rate were obtained for all peaks, but with different slopes (Figure 3b). 


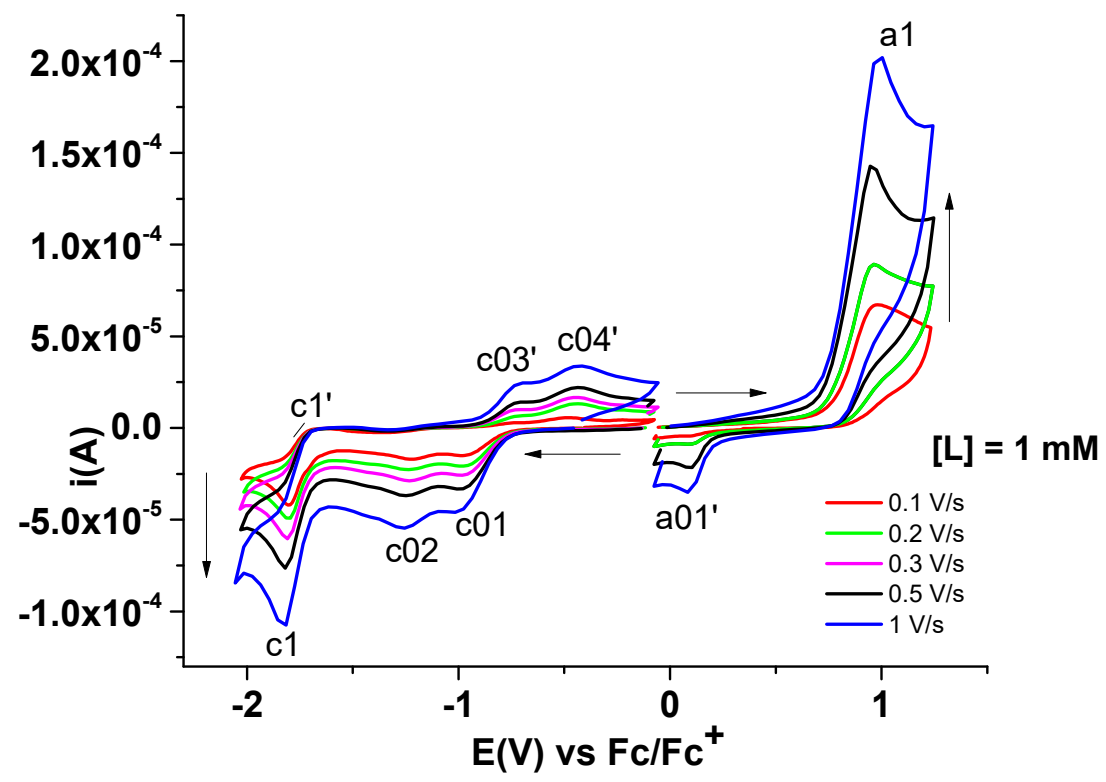

(a)

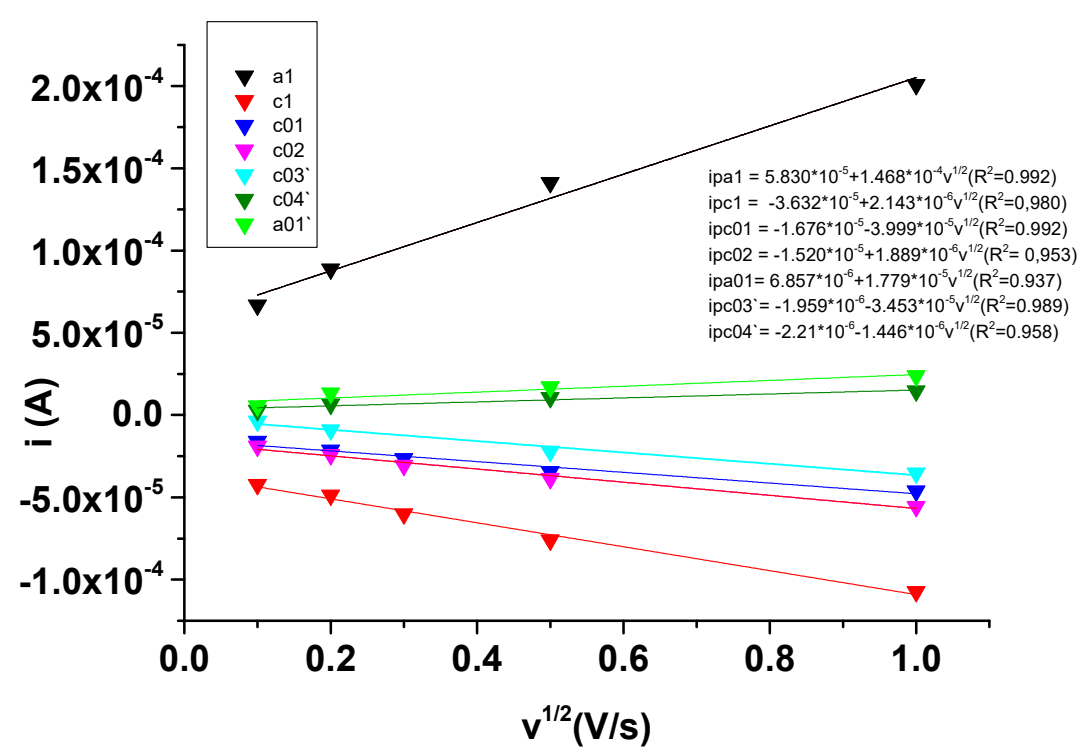

(b)

Figure 3. CV curves at different scan rates in $1 \mathrm{mM}$ solution of $\mathbf{L}(\mathbf{a})$ and linear dependences of the currents for the peaks a1, c01, c02 and $\mathrm{c} 1$ on the square root of the scan rate (b).

Figure 4 shows the $\mathrm{CV}$ curves $(0.1 \mathrm{~V} / \mathrm{s})$ obtained on different potential ranges, and Table 1 assumes the peak potentials (V) and currents from DPV and CV curves for $\mathbf{L}(1 \mathrm{mM})$, and the characteristics of processes for each peak, all estimated from CV and DPV curves. From the potential shift between the peak in the direct and reverse scans (compared with the corresponding shifts for reversible systems, such as ferrocene/ferricenium) and from the scan rate's influences on peak current and potential, the processes have been evaluated as reversible, quasireversible and irreversible. The corresponding peaks of $\mathrm{c} 1, \mathrm{c} 3$ and $\mathrm{a} 1$ in the reverse scans have been denoted with $\mathrm{c1}^{\prime}, \mathrm{c} 3^{\prime}$ and $\mathrm{a} 1^{\prime}$, respectively. Most of the processes in Table 1 are irreversible, but in the cathodic domain the peaks c1 and c3 are quasireversible (having as response the peaks $c 1^{\prime}$ and $c 3^{\prime}$ ). 


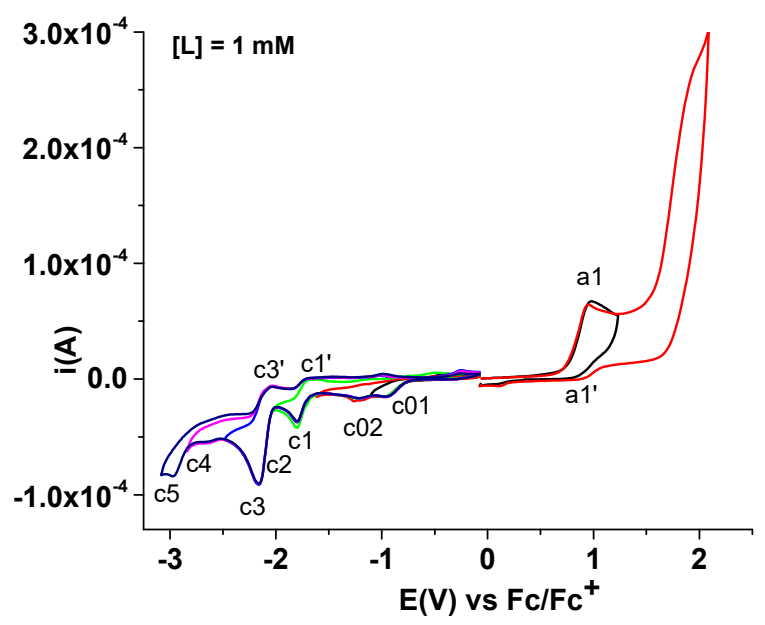

Figure 4. CV curves at different potential ranges for $1 \mathrm{mM}$ solution of $\mathbf{L}$.

Table 1. Peak potentials (v) vs. $\mathrm{Fc} / \mathrm{Fc}^{+}$and currents from DPV and CV $([\mathbf{L}]=1 \mathrm{mM})^{1}$.

\begin{tabular}{cccccc}
\hline Peak & \multicolumn{2}{c}{ E(V) } & \multicolumn{2}{c}{$\mathbf{I} \times \mathbf{1 0}^{5}$ (A) } & $\begin{array}{c}\text { Process } \\
\text { Characteristics }\end{array}$ \\
\hline & CV & DPV & CV & DPV & \\
a1 & +1.010 & +0.910 & +10.9 & +2.020 & irreversible \\
a1' & +0.885 & - & +2.56 & - & - \\
c01 & -0.955 & -0.944 & -1.86 & -0.276 & irreversible \\
c02 & -1.240 & -1.190 & -1.37 & -0.276 & irreversible \\
c1 & -1.800 & -1.760 & -5.28 & -1.600 & quasireversible \\
c1 & -1.690 & - & -2.84 & - & - \\
c2 & -2.094 & -2.108 & -8.61 & -2.210 & irreversible \\
c3 & -2.170 & -2.170 & -14.00 & -2.850 & quasireversible \\
c3 & -2.058 & - & -5.15 & - & - \\
c03' & -0.716 & - & -2.43 & - & - \\
c4 & -2.700 & -2.610 & -9.25 & -2.850 & irreversible \\
c04' & -2.058 & - & -3.52 & - & - \\
c5 & $-2,980$ & -2.920 & -12.3 & -0.706 & irreversible \\
\hline
\end{tabular}

${ }^{1}$ Read for CV from Figures 2 and 3, and for DPV from Figure 2.

A comparison between the RDE curves obtained at different rotation rates (500-1500 rpm) and the DPV curve (in absolute currents) can be seen in Figure 5. There is no RDE wave in the anodic domain corresponding to the DPV peak a1, one wave for the oxidation of the supporting electrolyte (with limiting currents decreasing with the rotation rate) and two waves (w1 and w2) in the cathodic domain (corresponding mainly to the DPV peaks c1 and c2-c3 (with limiting currents increasing with the rotation rate). This shape of RDE curves can be attributed to the formation of insulating polymer film (which drops the current to the baseline), as shown further. If the rotation rate is higher the film formation is not favored, and the electrolyte oxidation processes occur better. 


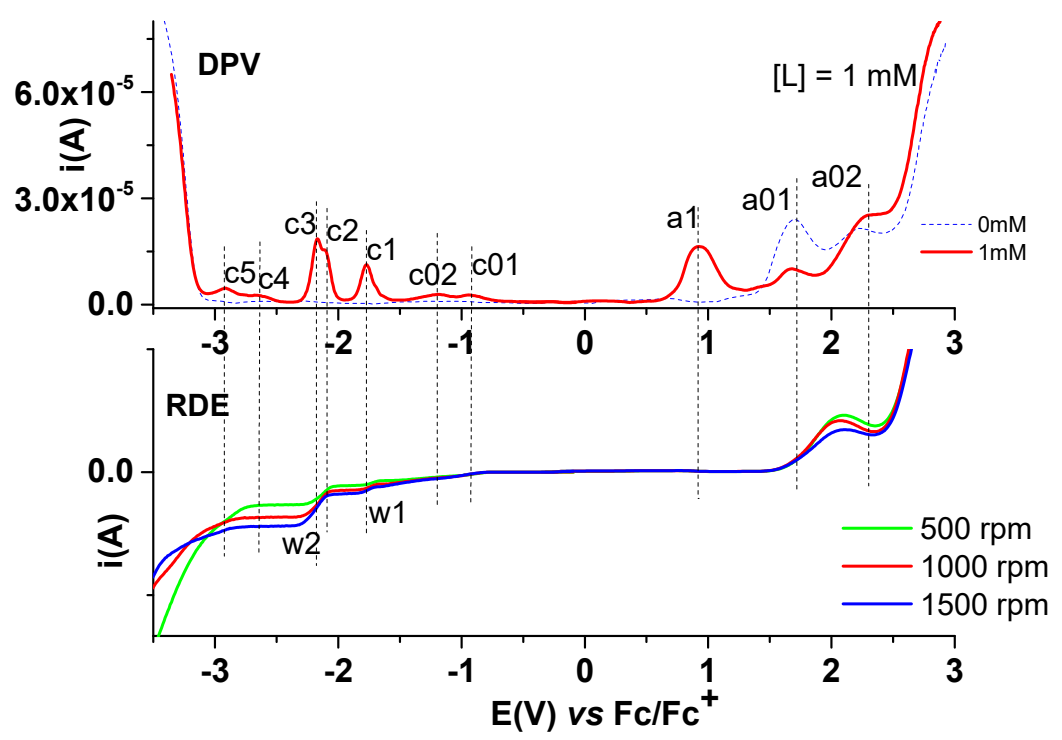

Figure 5. RDE curves at different rotation rates in parallel with the DPV curves (in absolute currents).

\subsection{Mechanistic Schemes of $\boldsymbol{L}$ Electrochemical Processes}

From the data given above it seems that $\mathbf{L}$ has only one important oxidation process, a1, with a peak at $0.91 \mathrm{~V}$. It is a multi-electron transfer, because when keeping the electrode at $0.8 \mathrm{~V}$ a completely irreversible process occurs, leading to an insulating film. This process can be rationalized as the formation of an azulene radical-cation, followed by an azulene dication, which decays as a polymer material based on indan or alkylbenzene structures (Figure 6). The tetrazole moiety decays as nitrogen and carbon dioxide. In the cathode region, the processes are partially reversible. They exist mainly in two reduction zones: the first at $-1.76 \mathrm{~V}$ could be attributed to the formation of a hydrazine compound, which is reduced further at around $-2.1 \mathrm{~V}$ with the initial formation of the 1-azulenamine and 5-tetrazolamine (Figure 6). It is very possible that these amines are reduced further to guanidine, nitrogen and partial- hydrogenated azulenamines.

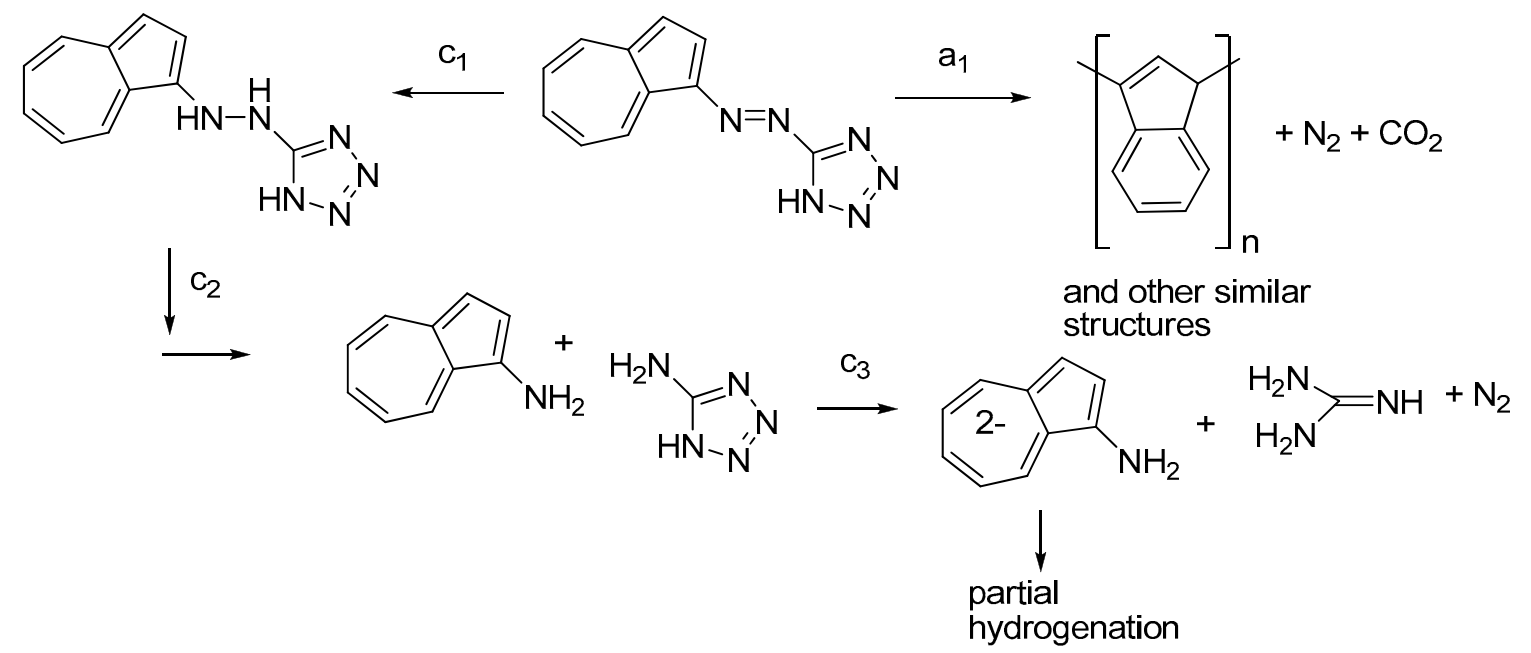

Figure 6. Mechanistic steps in electrochemical oxidation (a1) and reduction (c1, etc.) of $\mathbf{L}$.

The oxidation and reduction potentials taken from DPV curves (as potentials of a1 and c1 peaks) and shown in Table 1 are in good agreement with those observed for other azulene-1-azo heterocycles (Table 2). If we examine the values in Table 2, it can be seen that the oxidation and reduction potentials increase and decrease, respectively, with the heterocycle electronegativity. 
Table 2. Redox potentials of some 1-azulene-azo-heterocycles Ar-N=N-Het for different structures of heterocycle (Het).

\begin{tabular}{cccc}
\hline Heterocycle (Het) & Eox $(\mathbf{V})$ & Ered $(\mathbf{V})$ & Reference \\
\hline 2-thiazol & 0.601 & -1.406 & {$[2]$} \\
4-pyridine & 0.713 & -1.488 & {$[2]$} \\
4-methylpiridinium & $0.859 / 0.930$ & $-0.789 /-0.870$ & {$[2]$} \\
1,3,4-thiodiazole & 0.995 & -1.153 & {$[9]$} \\
tetrazole & 0.91 & -1.76 & Present paper \\
\hline
\end{tabular}

The relatively high reduction potential of tetrazole-azo-azulene $\mathbf{L}$ (of about - $1.8 \mathrm{~V}$ ) can be explained by partial ionization of the compound at the cathode. The tetrazole moiety has acidic properties and could become negatively charged and therefore more difficult to reduce (Figure 7). Another explanation could be the presence of nonbonding nitrogen electrons, which shield the electrode, making the interaction more difficult (overpotential).
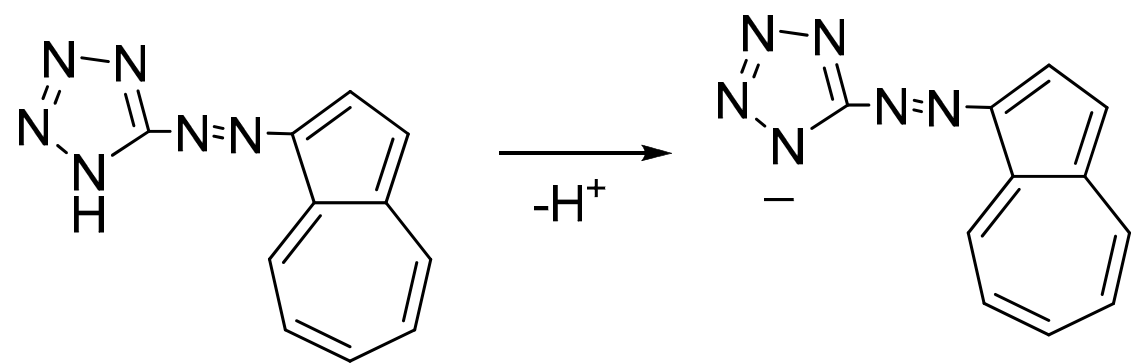

Figure 7. Tetrazole ionization.

\subsection{Modified Electrodes Based on PolyL}

By cycling the potential in the anodic domain, the electrode is covered by an insulating film, as was proven by recording the $\mathrm{CV}$ of the ferrocene probe. The original reversible ferrocene signal decreased significantly after covering. The covering process is better controlled when the film is prepared by CPE at potentials around that of a1 peak (Figure 6). PolyL-modified electrodes prepared by CPE from a $1 \mathrm{mM}$ solution of $\mathrm{L}$ in $\mathrm{CH}_{3} \mathrm{CN}$ and TBAP were transferred into a ferrocene probe solution. The CV curves of modified electrodes have been compared to those of bare electrode. The curves of polyL-modified electrodes obtained by CPE when using different potentials and charges are shown in Figures 8 and 9, respectively.

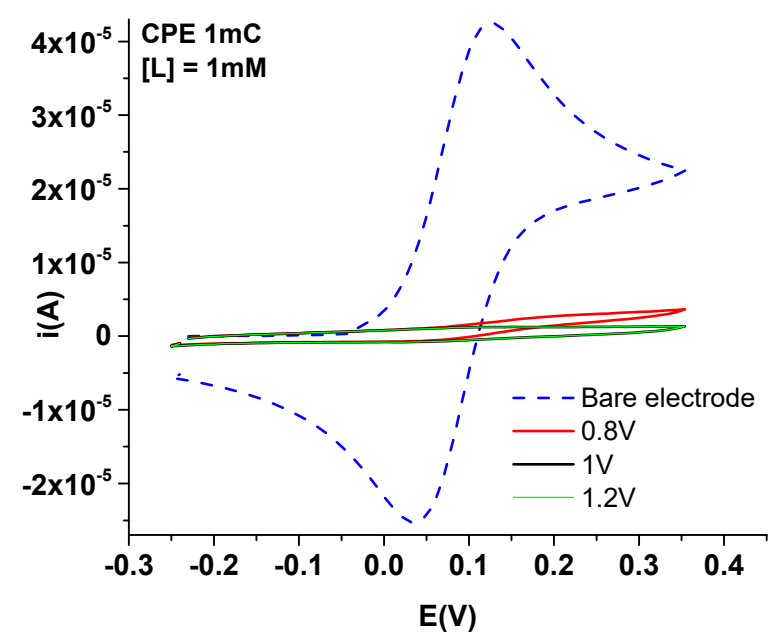

Figure 8. CV $(0.1 \mathrm{~V} / \mathrm{s})$ curves in $1 \mathrm{mM}$ ferrocene for polyL-modified electrodes prepared by CPE at $+0.8,+1$ and $+1.2 \mathrm{~V}$ in $\mathbf{L}$ solution $(1 \mathrm{mM})$ using the electropolymerization charge of $1 \mathrm{mC}$. 


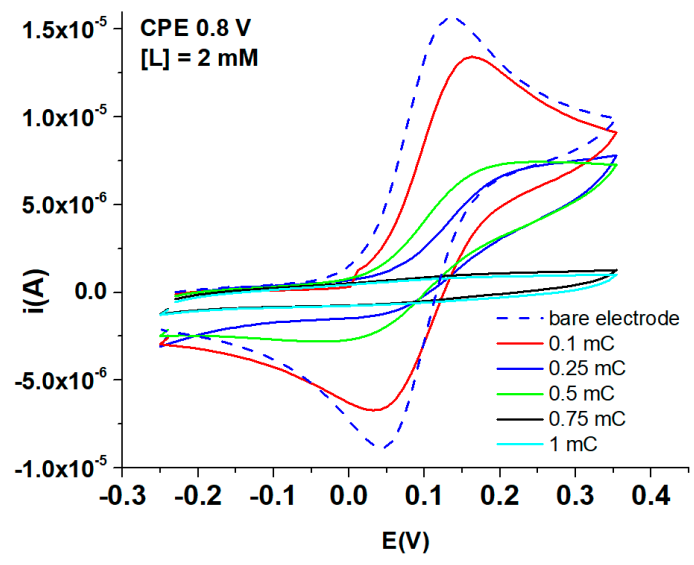

(a)

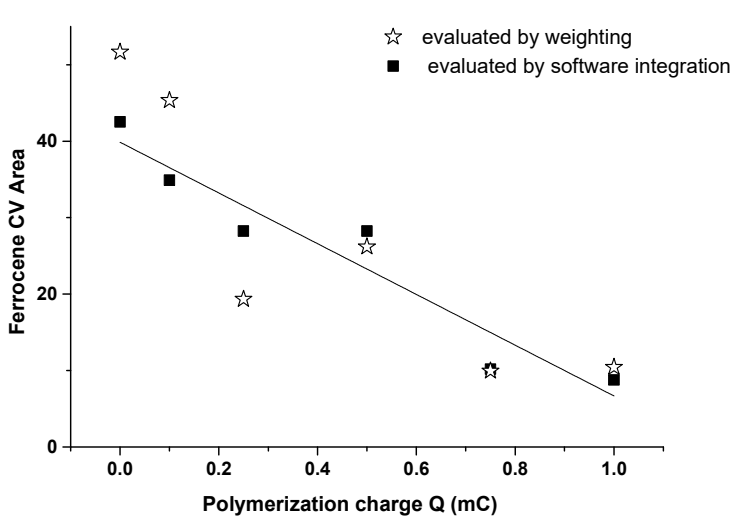

(b)

Figure 9. $\mathrm{CV}(0.1 \mathrm{~V} / \mathrm{s})$ curves in ferrocene solution $\left(1 \mathrm{mM}\right.$ in $0.1 \mathrm{M}$ TBAP/ $\left.\mathrm{CH}_{3} \mathrm{CN}\right)$ of polyL-modified electrodes prepared by $\mathrm{CPE}$ at $+0.8 \mathrm{~V}$ in $\mathbf{L}$ solution $(1 \mathrm{mM})$ in $0.1 \mathrm{M} \mathrm{TBAP} / \mathrm{CH}_{3} \mathrm{CN}$ using different electropolymerization charges (a) and dependence of the of peak area on ferrocene (calculated by the integration of the CV curve 1st cycle between $-0.25 \mathrm{~V}$ and $+0.35 \mathrm{~V})$ on the polymerization charge $(\mathbf{b})$.

From the experiments shown in Figure 8, in which the potential was varied using the same polymerization charge $(1 \mathrm{mC})$, the signal of ferrocene was flatter for the modified electrodes which were obtained at 1 and $1.2 \mathrm{~V}$, compared to the one prepared at $0.8 \mathrm{~V}$. However, there is not a big difference between the modified electrodes; they all show good coverage. The potential of $0.8 \mathrm{~V}$ has been chosen further to prepare modified electrodes by CPE in view of heavy metal ion complexation. This potential ensures a good coverage of the electrode with the polymer film, as was also demonstrated by SEM and AFM investigations (see further). The modified electrodes prepared at this potential led to good results in the detection of heavy metals (see further), indicating a good coverage of the electrode with complexing units.

In the experiments shown in Figure 9, wherein CPE was held at the potential of $+0.8 \mathrm{~V}$ and we used different electropolymerization charges $(0.1-1 \mathrm{mC})$, the CVs of modified electrodes prepared by CPE were compared after immersion in ferrocene probe solution. The electrode that was modified and prepared at 0.75 and $1 \mathrm{mC}$ was more flattened than the one prepared at $0.1,0.25$ and $0.5 \mathrm{mC}$ (which approximates the bare electrode). A linear decrease was found for the CV ferrocene area when the charge used for the film preparation increased (Figure 9b). This dependence can be used to evaluate the electrode coverage degree. For further recognition experiments, the modified electrodes were obtained at a charge of $1 \mathrm{mC}$, which was chosen since better coverage of the electrode occurs at this charge.

\subsection{Characterization of PolyL-Modified Electrode Surfaces}

PolyL modified electrodes were investigated by AFM and SEM to compare the morphologies of the polyL films obtained in different conditions. PolyL films were prepared by CPE using the same electropolymerization charge per $\mathrm{cm}^{2}$. This charge corresponds to that which was used in the preparation of the electrodes that were modified and have been used for the analysis of the heavy metals (see further).

Several selected topography images of the polymer acquired by SEM at different magnifications are seen in Table 3. They show a relatively uniform arrangement of the polymer matrix surface. The surface images show also different mechanical defects (scratches of the surface area) due to the sample preparation process. PolyL films of the samples deposited by CPE using constant potential (1 V) and different electropolymerization charges were analyzed by AFM technique (Tables 3 and 4). Each white point is an agglomeration of polymer films, having the same composition as the polymer background. 
Table 3. SEM at $\times 250 \mathrm{~K}$ and AFM micrographs for films obtained by CPE at $1 \mathrm{~V}$ with different polymerization charges ${ }^{2}$.

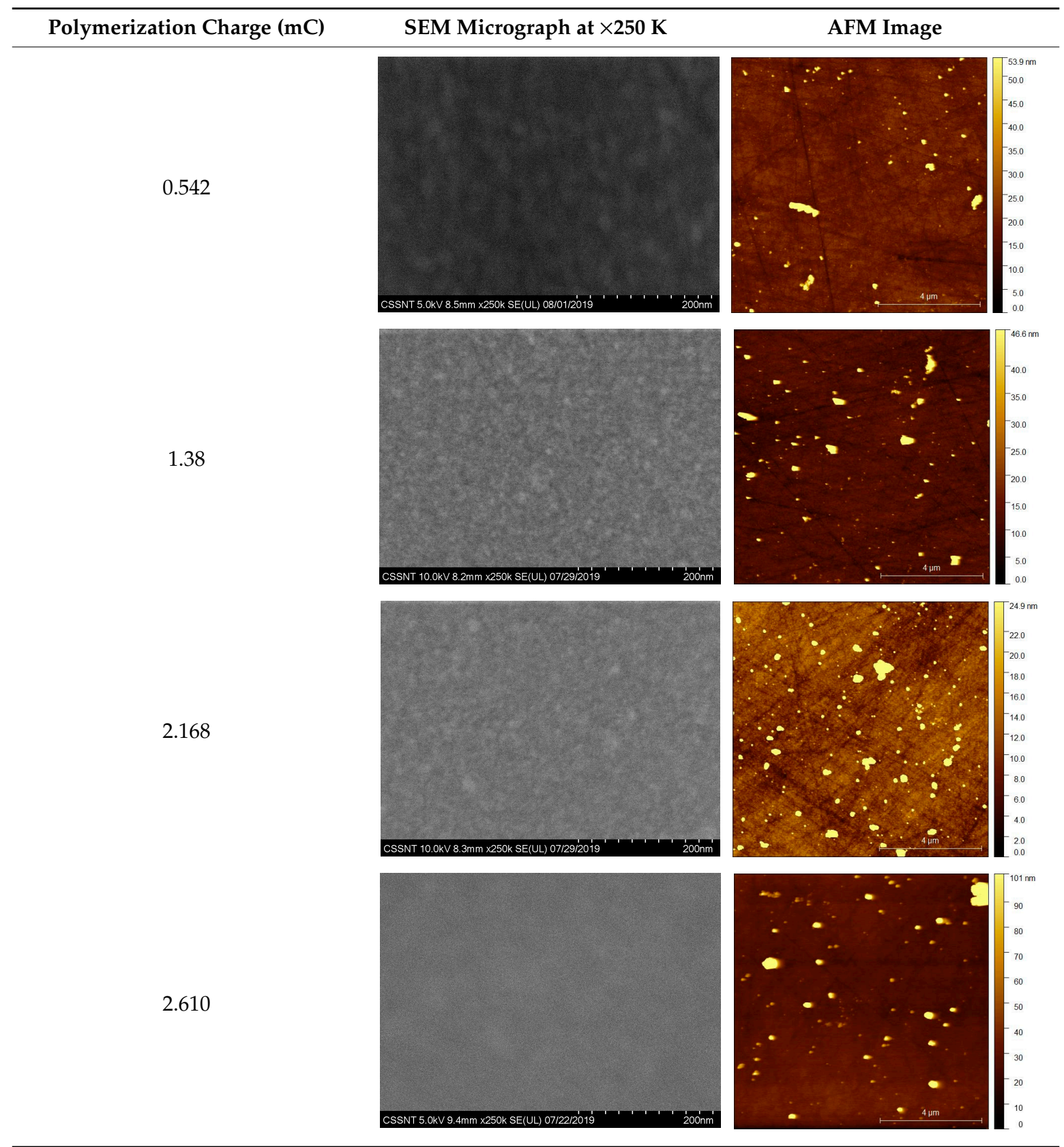

${ }^{2}$ The films were obtained from $\mathbf{L}$ solution $(1 \mathrm{mM})$ in $\mathrm{CH}_{3} \mathrm{CN}$ containing $0.1 \mathrm{M}$ TBAP.

Table 4. Surface characteristics of the films obtained by CPE at $1 \mathrm{~V}$ using different charges from AFM experiments.

\begin{tabular}{cccc}
\hline Sample & Polymerization Charge $(\mathbf{m C})$ & RMS $(\mathbf{n m})$ & Ra $(\mathbf{n m})$ \\
\hline P1 & 0.542 & 6.074 & 2.344 \\
P2 & 1.380 & 6.716 & 2.365 \\
P3 & 2.168 & 11.981 & 3.791 \\
P4 & 2.610 & 15.810 & 5.840 \\
\hline
\end{tabular}

Table 3 shows the surface micrographs obtained in AFM analysis for different polyL-modified electrodes. The topography of AFM images showed the presence of many columnar shape 
characteristics. The surface roughness parameter, calculated from the acquired topographic images, increases with the electropolymerization charge. RMS results (Table 4 and Figure 10) confirm that the particle agglomeration tendency on the electrode surface increases as the film becomes thicker (when electropolymerization charge increases). This CPE procedure ensures a good coverage of the electrode with the polymer film.

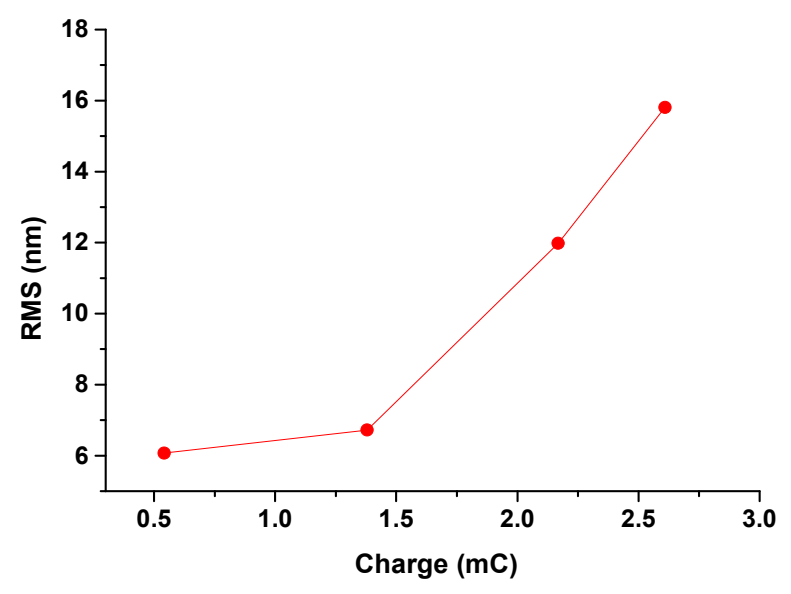

Figure 10. RMS dependence on electropolymerization charge.

\subsection{Heavy Metal Sensing}

Electrodes that were modified with polyL and were likewise prepared by CPE $(0.8 \mathrm{~V}, 1 \mathrm{mC})$ in an L solution with a concentration of $1 \mathrm{mM}$ in $0.1 \mathrm{M} \mathrm{TBAP} / \mathrm{CH} 3 \mathrm{CN}$, have been used to the recognition of heavy metals [15]. The recognition has been tested by preconcentration and anodic stripping. The cleaning of the modified electrodes with acetonitrile was followed by their immersion in the transfer solution, which consisted of acetate buffer $(0.1 \mathrm{M})$ at $\mathrm{pH}$ 5.5. After 15 cycles of equilibration (by $\mathrm{CV}$ between -0.9 and $+0.6 \mathrm{~V}$ with a the scan rate of $0.1 \mathrm{~V} / \mathrm{s}$ ) and 15 cycles of overoxidation (by $\mathrm{CV}$ between -0.2 and $+1.5 \mathrm{~V}$ with a the scan rate of $0.1 \mathrm{~V} / \mathrm{s}$ ), the modified electrodes were taken out from the cell, washed with water and put in synthetic solutions with different concentrations of heavy metals ions, under magnetic stirring for $15 \mathrm{~min}$. After that, the modified electrodes were removed from the accumulation solution, immersed in a solution of acetate buffer having a $\mathrm{pH}$ of 5.5 and polarized at $-1.2 \mathrm{~V}$. At this potential all cations were reduced. Then the electrode was linearly polarized using DPV method between $-1.2 \mathrm{~V}$ and $+0.5 \mathrm{~V}$. Their DPV stripping current peaks were then recorded. For every heavy metal, a calibration curve was drawn (Figure 11).

For the DPV stripping currents resulting from each ion's concentration in the accumulation solution, the recognition signals decreased in the order: $\mathrm{Pb}>\mathrm{Hg}>\mathrm{Cu}>\mathrm{Cd}$. $\mathrm{Pb}$ was the one that had the best analytical signals, and has a large linear domain between $5 \times 10^{-8}$ and $10^{-6} \mathrm{M}$. Taking into account the linear range obtained for $\mathrm{Pb}$ analysis, these results show that this new modified electrode is a promising alternative method for analyzing $\mathrm{Pb}$ in real waste waters. 


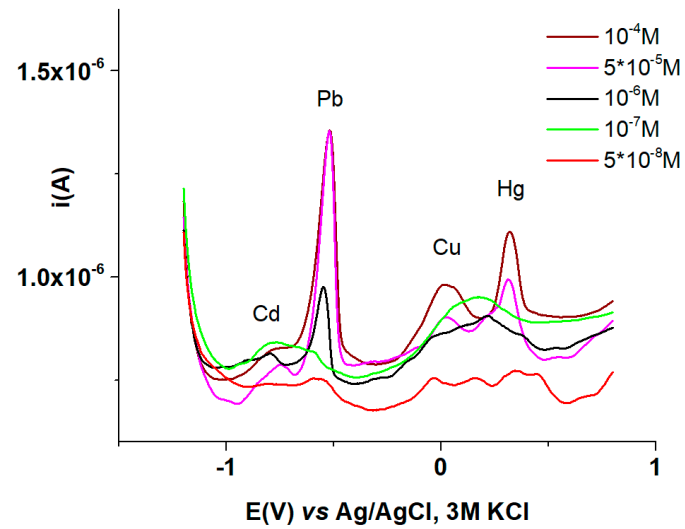

(a)

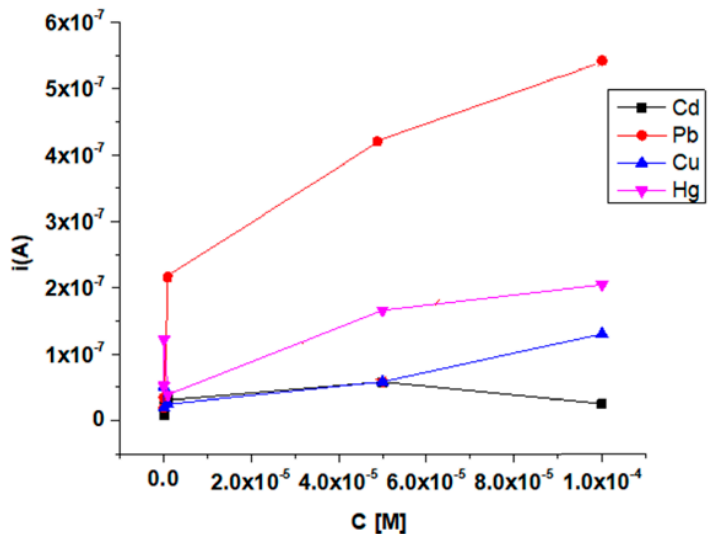

(b)

Figure 11. DPV stripping currents in acetate buffer at $\mathrm{pH} 5.5$ for polyL-modified electrodes obtained by $\mathrm{CPE}(+0.8 \mathrm{~V}, 1 \mathrm{mC})$ in $\mathbf{L}$ solution $(1 \mathrm{mM})$ in $0.1 \mathrm{M} \mathrm{TBAP} / \mathrm{CH}_{3} \mathrm{CN}$, after being immersed in water containing different concentrations of heavy metals (a) and the DPV stripping current's dependence on heavy metal ion concentrations for $\mathrm{Cd}, \mathrm{Pb}, \mathrm{Cu}$ and $\mathrm{Hg}(\mathbf{b})$.

\section{Conclusions}

New modified electrodes based on (E)-5-(azulen-1-yldiazenyl)-1H-tetrazole (L) ligand have been obtained in order to get sensitive sensors for heavy metal ion detection. $\mathrm{L}$ electrochemical behavior has been investigated by cyclic voltammetry (CV) to establish the character of the processes occurring at different potentials. Differential pulse voltammetry has given the right numbers and potentials for these processes, and rotating disk electrode has confirmed the character established by CV and has given evidence for the polyL film's formation. Mechanistic schemes for the electrochemical processes occurring during the anodic and cathodic scans have been proposed in order to rationalize the obtained results. PolyL modified electrodes obtained by CPE at different potentials and charges were characterized after their transfer in the ferrocene solution. The integration of the ferrocene signal for the modified electrode can be a way to estimate the polymerization charge used for the film preparation.

The films deposited on the modified electrodes were examined by SEM and AFM and their main morphological characteristics have been established. SEM studies showed a relatively uniform coverage of the electrode's surface by the polymer and the presence of clusters, which were confirmed by AFM images that show many columnar shaped characteristics. RMS results confirmed that the particle agglomeration tendency on the electrode's surface increased as the electropolymerization charge increased. The study led to the finding the best potential at which this azulene ligand could be polymerized to ensure a good coverage of the electrodes with polyL films. The recognition of heavy metal ions using these polyL-modified electrodes has been done by preconcentration and anodic stripping. The signals evidenced all investigated cations at different concentrations, which varied in the order: $\mathrm{Cd}<\mathrm{Cu}<\mathrm{Hg}<\mathrm{Pb}$. The best response obtained for $\mathrm{Pb}$ led to a detection limit of $5 \times 10^{-8} \mathrm{M}$, and a linear domain between $5 \times 10^{-8}$ and $10^{-6} \mathrm{M}$. Thus, this new azulene-based electrode demonstrated its feasibility for heavy metal ion detection and its potential use in future applications. Optimum conditions for $\mathrm{Pb}$ ion detection using this new modified electrode sensing are being established in order to get the best conditions for its use in real water sample analysis.

Author Contributions: Conceptualization, E.-M.U. and P.D.; methodology, M.E.; validation, E.-M.U. and L.B.; data curation, L.B.; writing-original draft preparation, L.-B.E.; writing-review and editing, V.A. All authors have read and agreed to the published version of the manuscript.

Funding: This research was funded by UEFISCDI Romanian projects: ECSEL-H2020, OCEAN12 (Ctr. number 9/1.1.3H/20.01.2020, POC-SMIS code 129948) and MADEin4 (Ctr. number 8/1.1.3H/06.01.2020, POC-SMIS code 128826); 39PCCDI/2018 INTELMAT, PN-III-P1-1.1-TE-2016-0860, contract number 114/2018; PN-III-P2-2.1-PED-2019-0730, contract number 293PED/2020; PN-II-PT-PCCA-2013-4-2151 contract number 236/2014. 
Acknowledgments: The authors are grateful for the support from bilateral projects China-Romania contract number 68BM/2016 and France-Romania PN-III-P3-3.1-PM-RO-FR-2019-0309; and to Gabriela STANCIU from University Ovidius Constanta, Romania, Valentin STANESCU, Cecilia IORDACHE, and technician Ionut STANESCU from SC Analist SRL for their help in organizing activities and experimental work in the scope of the contract number 236/2014.

Conflicts of Interest: The authors declare no conflict of interest.

\section{References}

1. Welz, B.; Sperling, M. Atomic Absorption Spectrometry, 3rd ed.; Wiley-VCH: Weinheim, Germany, 1999.

2. Evans, E.H.; Day, J.A.; Palmer, C.D.; Price, W.J.; Smith, C.M.M.; Tyson, J.F. Atomic spectrometry update. Advances in atomic emission, absorption and fluorescence spectrometry, and related techniques. J. Anal. At. Spectrom. 2005, 20, 562-590. [CrossRef]

3. Zhang, Y.; Adeloju, S.B. Ultratrace determination of cadmium by cold vapor atomic absorption spectrometry after preconcentration with a simplified cloud point extraction methodology. Talanta 2015, 137, 148-155. [CrossRef] [PubMed]

4. Montes-Bayón, M.; DeNicola, K.; Caruso, J.A. Liquid chromatography-inductively coupled plasma mass spectrometry. J. Chromatogr. A 2003, 1000, 457-476. [CrossRef]

5. Harrington, C.F.; Clough, R.; Drennan-Harris, L.R.; Hill, S.J.; Tyson, J.F. Atomic spectrometry update. Elemental speciation. J. Anal. At. Spectrom. 2011, 26, 1561-1595. [CrossRef]

6. Philips, M.F.; Saianand, G.; Lee, K.-P. Development of a novel cyano group containing electrochemically deposited polymer film for ultrasensitive simultaneous detection of trace level cadmium and lead. J. Hazard. Mater. 2012, 237, 46-54. [CrossRef] [PubMed]

7. Kuddannaya, S.; Bao, J.; Zhang, Y. EnhancedIn VitroBiocompatibility of Chemically Modified Poly(dimethylsiloxane) Surfaces for Stable Adhesion and Long-term Investigation of Brain Cerebral Cortex Cells. ACS Appl. Mater. Interfaces 2015, 7, 25529-25538. [CrossRef]

8. Buica, G.-O.; Bucher, C.; Moutet, J.-C.; Royal, G.; Saint-Aman, E.; Ungureanu, E.M. Voltammetric Sensing of Mercury and Copper Cations at Poly(EDTA-like) Film Modified Electrode. Electroanalysis 2009, 21, 77-86. [CrossRef]

9. March, G.; Nguyen, T.D.; Piro, B. Modified Electrodes Used for Electrochemical Detection of Metal Ions in Environmental Analysis. Biosensors 2015, 5, 241-275. [CrossRef]

10. Buica, G.-O.; Ungureanu, E.-M.; Birzan, L.; Razus, A.C.; Popescu, L.-R.M. Voltammetric sensing of lead and cadmium using poly(4-azulen-1-yl-2,6-bis(2-thienyl)pyridine) complexing films. J. Electroanal. Chem. 2013, 693, 67-72. [CrossRef]

11. Birzan, L.; Cristea, M.; Tecuceanu, V.; Hanganu, A.; Ungureanu, E.-M.; Razus, A.C. 5-(Azulen-1-yldiazenyl)tetrazoles; Syntheses and Properties. Rev. Chim. 2020, 71, 251-264. [CrossRef]

12. Ungureanu, E.-M.; Buica, G.-O.; Razus, A.C.; Birzan, L.; Weisz, R.; Bujduveanu, M.-R. Electrochemical Study on 4-(azulen-1-yl)-2,6-bis(2-furyl)- and 4-(azulen-1-yl)-2,6-bis(2-thienyl)-pyridines. Rev. Chim. 2012, $63,27-33$.

13. Ungureanu, E.-M.; Razus, A.C.; Birzan, L.; Cretu, M.-S.; Buica, G.-O. Electrochemical study of azo-azulene compounds. Electrochim. Acta 2008, 53, 7089-7099. [CrossRef]

14. Birzan, L.; Cristea, M.; Draghici, C.C.; Tecuceanu, V.; Maganu, M.; Hanganu, A.; Razus, A.C.; Buica, G.-O.; Ungureanu, E.-M. Vinylazulenes chromophores: Synthesis and characterization. Dye Pigment. 2016, 131, 246-255. [CrossRef]

15. Buica, G.-O.; Lazar, I.-G.; Birzan, L.; Lete, C.; Prodana, M.; Enachescu, M.; Tecuceanu, V.; Stoian, A.B.; Ungureanu, E.-M. Azulene-ethylenediaminetetraacetic acid: A versatile molecule for colorimetric and electrochemical sensors for metal ions. Electrochim. Acta 2018, 263, 382-390. [CrossRef]

16. Pop, M.D.; Brincoveanu, O.; Cristea, M.; Buica, G.O.; Enachescu, M.; Ungureanu, E.M. AFM and SEM Characterization of Chemically Modified Electrodes Based on 5-[(azulen-1-yl) methylene]-2-thioxothiazolidin-4-one. Rev. Chim. 2018, 68, 2799-2803. [CrossRef]

17. Mandoc, L.R.; Arnold, G.L.; Ungureanu, E.-M.; Iordache, M.; Pascu, L.F.; Lehr, C.B. Electrochemical Studies for New Azulene Compounds. Rev. Chim. 2016, 67, 1451-1453.

18. Pop, M.D.; Anastasoaie, V.; Popescu, M.A.; Oprisanu, A.; Ungureanu, E.M.; Cristea, M. New Azulene Modified Electrodes for Heavy Metal Sensing. Rev. Chim. 2017, 68, 2172-2175. [CrossRef] 
19. Lazar, I.G.; Diacu, E.; Buica, G.O.; Ungureanu, E.M.; Arnold, G.L.; Birzan, L. The Heavy Metals Sensing Based on 2,6-Bis(-2-(Thiophen-3-yl)Vinyl)-4-(4,6,8-Trimethylazulen-1-yl)Pyrylium Modified Electrodes. Rev. Chim. 2017, 68, 2509-2513. [CrossRef]

20. Lazar, I.G.; Diacu, E.; Vasile, G.G.; Ungureanu, E.M.; Ivanov, A.A. Study of Analytical Parameters of a Differential Pulse Voltammetric Method using Chemically Modified Electrodes for Lead Analysis in Water. Rev. Chim. 2018, 69, 2311-2314. [CrossRef]

C 2020 by the authors. Licensee MDPI, Basel, Switzerland. This article is an open access article distributed under the terms and conditions of the Creative Commons Attribution (CC BY) license (http://creativecommons.org/licenses/by/4.0/). 